\title{
Obstructive sleep apnoea and cardiovascular disease in the developing world
}

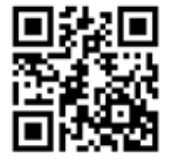

Obstructive sleep apnoea (OSA) is a common condition, with studies from the USA suggesting that the prevalence is $4 \%$ in men and $2 \%$ in women. ${ }^{[1]}$ The prevalence in other parts of the world is unknown but is likely to be similar.

The theory of epidemiological transition outlined by Omran ${ }^{[2]}$ suggests there are three basic stages: pestilence and famine, receding pandemics, and degenerative and man-made disease. The developed world, in general, is in stage 3 with lifestyle changes (diet, reduced activity, smoking) resulting in atherosclerosis and death from cardiovascular disorders and other non-communicable diseases. Improvements in availability of food, sanitation and healthcare in the developing world are leading to a move from pestilence and famine to an increased prevalence of non-communicable diseases, particularly diseases of the cardiovascular system. Cardiovascular disease accounts for approximately $30 \%$ of all deaths globally, $80 \%$ of these in low- and middle-income countries. ${ }^{[3]}$ South Africa illustrates a blend of epidemiological stages $-67 \%$ of deaths in 2011 were a result of communicable diseases, $11 \%$ (38\% of the non-communicable diseases) were due to cardiovascular disease. ${ }^{[4]}$

OSA is strongly associated with a number of cardiovascular diseases. Hypertension, stroke, arrhythmias and heart failure are prominent among these. The Wisconsin Sleep Cohort followed 1522 subjects and demonstrated greater mortality in those with severe OSA (19.1\%) compared with those with none (4\%). Cardiovascular mortality counted for $26 \%$ of deaths in those without OSA and $42 \%$ in those with severe OSA. ${ }^{[5]}$ Similarly, Marin et al. ${ }^{[6]}$ demonstrated a higher incidence of fatal cardiovascular events in those with untreated severe disease than those with mild disease ( $1.06 \mathrm{v}$. 0.55 events per 100 person years). Those patients with moderate or severe OSA who were treated with continuous positive airways pressure (CPAP) had rates of fatal and non-fatal cardiovascular events that were similar to those with no or mild disease.

Hypertension has the best documented association with OSA. Treatment with CPAP has a modest but significant effect on blood pressure, which is increased by better compliance with CPAP use for at least 4 hours per night, ${ }^{[7]}$ although this effect is only seen in those who have symptoms of excessive sleepiness. ${ }^{[8]}$ There is also evidence to suggest better outcomes after stroke and improved arrhythmia control, particularly atrial fibrillation, when OSA is diagnosed and treated. ${ }^{[9,10]}$

The article in this journal by Adeninyi et al. is important as it highlights the high prevalence of symptoms typical of OSA in medical patients in a developing country. Sleep problems have been harshly dealt with and largely ignored in developing countries to date. The transition from diseases of pestilence and famine to increasing numbers of non-communicable diseases means that, as suggested by Gersh et al., ${ }^{[11]}$ increasing emphasis will have to be placed on simple measures such as avoiding smoking and obesity and increasing exercise. More complex measures such as the appropriate use of drugs and the recognition and management of OSA will become increasingly more important.

\section{Richard Raine}

$M B C h B, M M e d(M e d), F C P(S A)$

Respiratory Clinic, Department of Medicine, Groote Schuur Hospital and University of Cape Town

\section{References}

1. Young T, Palta M, Dempsey J, Skatrud J, Weber S, Badr S. The occurrence of sleepdisordered breathing among middle-aged adults. N Engl J Med 1993;328(17):12301235. [http://dx.doi.org/10.1056/NEJM199304293281704]

2. Omran AR. The epidemiologic transition: A theory of the epidemiology of population change. Milbank Mem Fund Q 1971;49(4):509-538.

3. Gaziano TA. Cardiovascular disease in the developing world and its cost-effective management. Circulation 2005;112(23):3547-3553. [http:dx.doi.org/10.1161/ CIRCULATIONAHA.105.591792]

4. World Health Organization. Noncommunicable diseases country profiles: South Africa 2011. http://www.who.int/nmh/countries/en/ (accessed 10 Feb 2014).

5. Young T, Finn L, Peppard PE, et al. Sleep disordered breathing and mortality: Eighteen-year follow-up of the Wisconsin sleep cohort. Sleep 2008;31(8):1071-1078.

6. Marin JM, Carrizo SJ, Vicente E, Agusti AG. Long-term cardiovascular outcomes in men with obstructive sleep apnoea-hypopnoea with or without treatment with continuous positive airway pressure: An observational study. Lancet 2005;365(9464):1046-1053. [http://dx.doi.org/10.1016/S0140-6736(05)71141-7]

7. Sánchez-de-la-Torre M, Campos-Rodriguez F, Barbé F. Obstructive sleep apnoea and cardiovascular disease. Lancet Respir Med 2013;1(1):61-72 [http://dx.doi. org/10.1016/S2213-2600(12)70051-6].

8. Bratton DJ, Stradling JR, Barbé F, Kohler M. Effect of CPAP on blood pressure in patients with minimally symptomatic obstructive sleep apnoea: A meta-analysis using individual patient data from four randomised controlled trials. Thorax 2014;69(12):1128-1135. [http://dx.doi.org/10.1136/thoraxjnl-2013-204993]

9. Johnson KG, Johnson DC. Frequency of sleep apnea in stroke and TIA patients: A meta-analysis. J Clin Sleep Med 2010;6(2):131-137.

10. Ng CY, Liu T, Shehata M, Stevens S, Chugh SS, Wang X. Meta-analysis of obstructive sleep apnea as predictor of atrial fibrillation recurrence after catheter ablation. Am J Cardiol 2011;108(1):47-51. [http://dx.doi.org/10.1016/j.amjcard.2011.02.343]

11. Gersh BJ, Sliwa K, Mayosi BM, Yusuf S. Novel therapeutic concepts: The epidemic of cardiovascular disease in the developing world: Global implications. Eur Heart J 2010;31(6):642-648. [http://dx.doi.org/10.1093/eurheartj/ehq030]

S Afr Resp J 2015;21(1):2. DOI:10.7196/SARJ.7739 